\title{
Acetabular labral tear is associated with high pelvic incidence with or without femoroacetabular impingement morphology
}

\author{
Hyuck Min Kwon ${ }^{1} \cdot$ Byung-Woo Cho ${ }^{2} \cdot$ Sungjun $\mathrm{Kim}^{3} \cdot$ Ick-Hwan Yang ${ }^{2} \cdot \mathrm{Kwan} \mathrm{Kyu} \mathrm{Park}^{2} \cdot \mathrm{Nak}^{-H o o n} \mathrm{Son}^{4}$. \\ Woo-Suk Lee ${ }^{5}$
}

Received: 25 August 2021 / Accepted: 13 January 2022 / Published online: 31 January 2022

(c) The Author(s) 2022

\begin{abstract}
Purpose The aim of this study was to investigate the association between pelvic sagittal parameters and acetabular labral tears.

Methods Three-hundred and sixty-five patients (449 hips) who underwent magnetic resonance imaging (MRI) or magnetic resonance arthrogram (MRA) for hip pain were enrolled in this study. Pelvic sagittal parameters, including the pelvic incidence, pelvic tilt, and sacral slope, were measured with a standing lumbosacral lateral radiograph. All subjects were divided into two groups according to the presence or absence of radiologic acetabular labral tears and compared. Furthermore, the two groups were divided into subgroups according to whether femoroacetabular impingement (FAI) morphology was present or not and compared.

Results Pelvic incidence was greater in the labral tear group than in the non-labral tear group $\left(52.3^{\circ} \pm 8.2^{\circ}\right.$ versus $47.1^{\circ} \pm 6.8^{\circ}$, $p<0.001$ ). After accounting for potentially confounding variables, we found that higher age (odds ratio $1.04,95 \%$ confidence interval [CI] 1.02 to $1.06, p=0.001$ ), FAI (odds ratio $15.11,95 \%$ CI 7.43 to $30.75, p<0.001$ ), and high pelvic incidence (odds ratio $1.13,95 \%$ CI 1.09 to $1.17, p<0.001$ ) were independently associated with acetabular labral tear. When only the patients without FAI (308 hips) were divided into groups with and without acetabular labral tear, we found that higher age (odds ratio 1.03, 95\% CI 1.01 to 1.06, $p=0.008$ ) and high pelvic incidence (odds ratio 1.15 , 95\% CI 1.11 to $1.19, p<0.001$ ) were independently associated with acetabular labral tear.
\end{abstract}

Conclusion Acetabular labral tear is associated with high pelvic incidence with or without FAI morphology. Level of evidence III.

Keywords Acetabular labral tear $\cdot$ Pelvic incidence $\cdot$ Femoroacetabular impingement

Woo-Suk Lee

wsleeos@yuhs.ac

Hyuck Min Kwon

hyuck7777@yuhs.ac

Byung-Woo Cho

chobw0704@yuhs.ac

Sungjun Kim

agn70@yuhs.ac

Ick-Hwan Yang

IHYANG@yuhs.ac

Kwan Kyu Park

kkpark@yuhs.ac

Nak-Hoon Son

nhson@yuhs.ac
1 Department of Orthopedic Surgery, Yongin Severance Hospital, Yonsei University College of Medicine, Seoul, Korea

2 Department of Orthopedic Surgery, Severance Hospital, Yonsei University College of Medicine, Seoul, Korea

3 Department of Radiology, Gangnam Severance Hospital, Yonsei University College of Medicine, Seoul, Korea

4 Clinical Research (Biostatistician), Yongin Severance Hospital, Yonsei University College of Medicine, Seoul, Korea

5 Department of Orthopedic Surgery, Gangnam Severance Hospital, Yonsei University College of Medicine, 211 Eonju-ro, Gangnam-gu, Seoul 06273, Korea 


\section{Introduction}

Even though differential diagnosis is difficult due to complex pathological structure and acetabular dysplasia and ligamentous laxity might be the cause of groin or hip pain, acetabular labral tears have been reported as the cause of $22-55 \%$ of cases of groin or hip pain due to the location of pain-sensing free nerve endings in the labrum $[26,34,36]$. Although several studies have reported a high prevalence of asymptomatic acetabular labral tears in magnetic resonance imaging (MRI) [35, 40], some etiologies of acetabular labral tear have been investigated. Femoroacetabular impingement (FAI) is a bony morphology (cam or pincer type) and abnormal articulation of the femoral head and acetabulum that is associated with acetabular labral tears $[28,29]$. FAI is considered one of the primary predisposing factors to acetabular labral tear due to impinging the anterior-superior portion of the labrum [17]. However, symptomatic acetabular labral tears are known to be common in patients without FAI as well as those with FAI $[3,25]$. It is also well known for degenerative acetabular labral tears to be associated with degenerative changes of the hip joint $[2,36]$. Some acetabular labral tears could be related to acetabular trauma and traumatic labral tears among athletes [5].

The spinopelvic sagittal parameter of pelvic incidence (PI) is found to be in the upright position by determining the shape and orientation of the lower limbs and spine, which is independent of the patient position and pelvic orientation [18]. It is defined as the angle between the line perpendicular to the midpoint of the sacral plateau and the line from this point to the center of the femoral head [22], and it is commonly measured on standing lateral lumbosacral radiograph images. Due to functional hip anatomy and the interrelationship among lumbar spine, pelvis, and hip kinematics, the impact of the PI angle with mechanical stresses on the hip joint is well recognized clinically [14, 20]. Some studies have determined that higher PI among younger individuals may contribute to the development of hip osteoarthritis due to biomechanical adaptations of the pelvis and decreased femoral head coverage $[11,18]$. Some studies have also determined that patients with the cam-type or pincer-type FAI have smaller PI values than the healthy population [10]. Although this pelvic sagittal parameter influences the load across the hip joint and acetabular labrum, the effect of PI on acetabular labral tears is not well understood, especially in patients without FAI.

The purpose of this study was to investigate the association between pelvic sagittal parameters and acetabular labral tears. Based on the findings of previous studies mentioned above that abnormal pelvic sagittal parameters increase the mechanical forces applied to the hip joint, we hypothesized that abnormal pelvic sagittal parameters would be associated with acetabular labral tears. The hypotheses of the current study were that assessment of the association between pelvic sagittal parameters and acetabular labral tears in patients with hip pain or groin pain would be helpful in evaluating the acetabular labral tears.

\section{Materials and methods}

From March 2010 to December 2019, the Institutional Review Board (IRB)-approved database of 640 patients (Institutional Review Board of Yongin Severance Hospital, IRB \# 9-2020-0051) who met the following three criteria in an outpatient clinic visit was retrospectively reviewed: (1) groin pain or hip pain and a mechanical symptom, such as clicking or giving way without trauma history; (2) symptom not improving with 3 months of conservative treatment; and (3) plain radiography (anteroposterior pelvis or hip radiograph, frog-leg lateral radiograph, and standing lumbosacral lateral radiograph) and MRI or magnetic resonance arthrogram (MRA). Only patients between the ages of 18 and 60 years were included. Patients were excluded if they had any of the following: a history of previous ipsilateral hip surgery or spine fusion surgery, or radiographic abnormalities, such as degenerative osteoarthritis (Tönnis Grade $\geq 1$, which corresponds to increased sclerosis of the head and acetabulum, slight joint space narrowing, and slight lipping at the joint margins) [7]; traumatic osteoarthritis; osteonecrosis of the femoral head; rheumatologic disorder, such as ankylosing spondylitis or rheumatic arthritis; or a tumorous condition. After applying the above-mentioned criteria, 365 patients (449 hips) were finally included in this study (Fig. 1). Of the 449 images in this study, only nine images had MRA images that were obtained after $10-15 \mathrm{~mL}$ of a $2 \mathrm{mmol} / \mathrm{L}$ diluted solution of gadopentate-dimeglumine was injected intraarticularly, and most were 3.0 T MRI.

\section{Radiologic assessment}

Radiologic acetabular labral tear of patients was confirmed by MRI or MRA. An acetabular labral tear on the MR image was defined as an irregular labrum shape, a non-triangular labrum, a thickened labrum with no labral recess, a labrum with increased signal intensities on the $\mathrm{T} 1$ images, or labral detachment from the acetabular labrum [30]. All subjects were divided into two groups according to the presence or absence of radiologic acetabular labral tears. Furthermore, MRI or MRA and plain radiography were used to measure the alpha angle, lateral center-edge angle, typical pistol grip deformity, crossover sign, posterior wall sign, and ischial spine sign. The alpha angle was defined as the angle between the bisection of the femoral axis with a line connecting the 
640 patients with the following 3 conditions were reviewed

(between March 2010 to December 2019)

1. Groin pain or hip pain and mechanical symptom such as clicking, giving way without trauma history

2. Symptom was not improved with conservative treatment for 3 months.

3. MRI or MRA was evaluated.

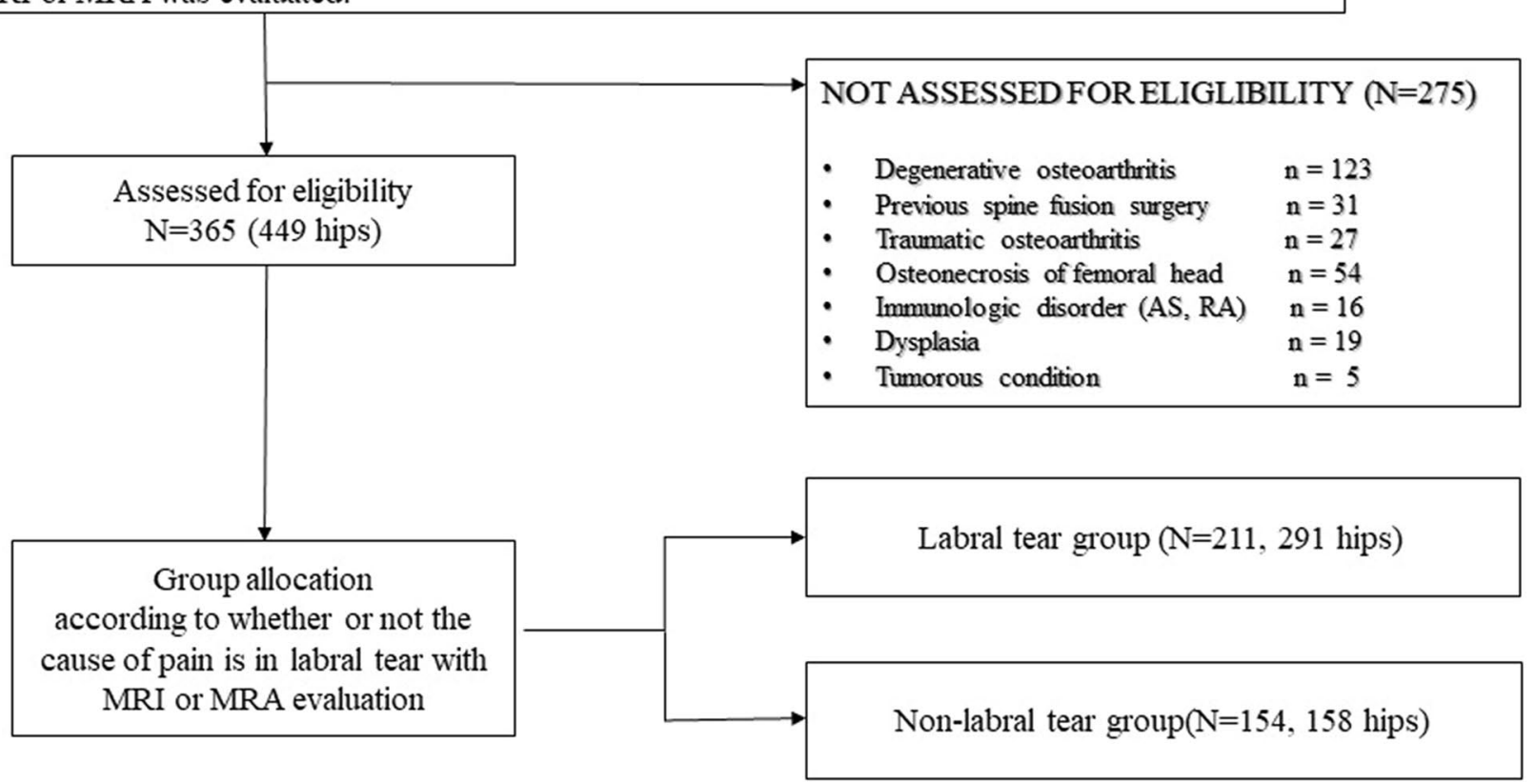

Fig. 1 Flowchart of patient inclusion in the study

center of the femoral head to the point where asphericity began in the oblique axial view on MRI or frog-leg lateral radiography [31, 39]. A pistol grip deformity, crossover sign, posterior wall sign, and ischial spine sign on a standard anterior-posterior hip plain radiography were evaluated [44]. The lateral center-edge angle was measured by drawing 3 lines on the anterior-posterior hip plain radiography: (1) a horizontal line connecting the bilateral inferior of teardrops, (2) a line through the center of the femoral head, perpendicular to line 1, and (3) a line through the center of the femoral head, passing through the most superolateral point of the acetabular sourcil. The angle created by lines 2 and 3 is the lateral center-edge angle [44]. The anterior center-edge angle was measured by drawing 2 lines on the false-profile view: (1) a vertical line through the center of the femoral head and (2) a line connecting the center of the femoral head and the most anterior point of the acetabular sourcil. The angle created by these two lines is the anterior center-edge angle [7]. On the basis of the above-mentioned radiologic findings, these three types of FAI morphology were considered: (1) cam type, characterized by the presence of the typical pistol grip deformity or alpha angle $>55^{\circ}$, (2) pincer type, characterized by the presence of a crossover sign or an lateral center-edge angle $>40^{\circ}$, and (3) mixed type, meeting the radiographic criteria for both cam and pincer types [1, $31,42]$. The acetabular labral tear and non-acetabular labral tear groups were each divided into subgroups according to whether or not FAI morphology was present.

The synovial herniation pit that is formed by herniation of soft tissue through erosion or perforation at the reactive interface area in the femoral neck was investigated using MR imaging [33]. A paralabral cyst in both intra- and extraarticular locations was defined as a well-defined fluid signal abnormality in direct contact with the acetabular labrum on MR imaging [21]. The presence of acetabular chondral pathology such as cartilage denudation or full-thickness cartilage defects was investigated during the MR imaging evaluation. Cartilage denudation was defined by MR findings of linear high signal intensity paralleling the subchondral bone plate within to the acetabular cartilage with chondral surface irregularity, and full-thickness cartilage defects were defined by extending to the subchondral bone [23, 32].

The pelvic sagittal parameters, including pelvic incidence, pelvic tilt, and sacral slope, were measured for all patients with a standing lumbosacral lateral radiograph (Fig. 2). Pelvic incidence was measured as the angle between the line perpendicular to the midpoint of the sacral plateau and the line from this point to the center of the femoral head 


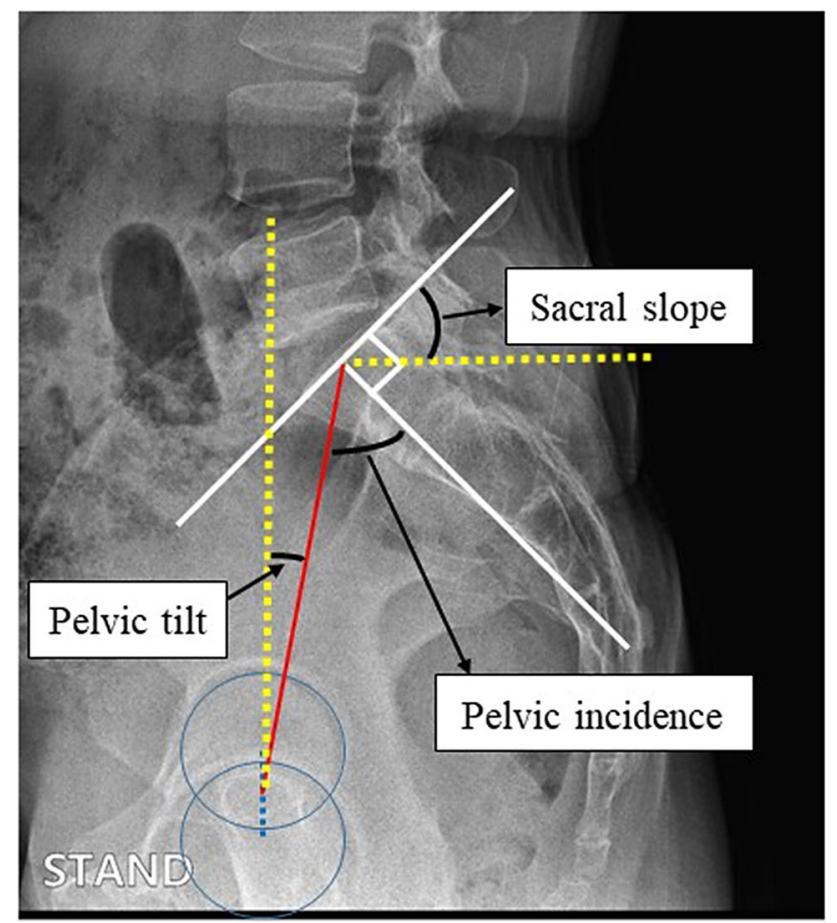

Fig. 2 Pelvic sagittal parameters based on standing plain radiography

[18]. Pelvic tilt was measured as the angle between the line joining the midpoint of the coxofemoral joint's axis to the center of the S1 endplate and the vertical reference line. Sacral slope was measured as the angle between the line tangential to the superior endplate of S1 and the horizontal plane. All measurements were performed by one radiologist and one orthopedic surgeon. All of the measured angles were allowed one decimal digit. The degree of measurement reliability was evaluated using intraclass correlation coefficients (ICC). Calculation of the ICC was performed by one experienced radiologist and one experienced orthopedic surgeon. For the ICC, values less than 0.2 were considered to indicate poor agreement; $0.21-0.40$, fair agreement; $0.41-0.60$, moderate agreement; $0.61-0.80$, good agreement; and above 0.80, excellent agreement [19]. The ICC for both intraobserver reliability and interobserver reliability were greater than 0.85 . In particular, the presence of acetabular labral tear, the presence of FAI morphology, and the ICC of pelvic incidence were $0.915,0.936$, and 0.867 , respectively.

\section{Statistical analysis}

Chi-square test and $t$ test were performed to compare the labral tear and non-labral tear groups. A multivariate logistic regression test with $95 \%$ CIs was performed to analyze the independent risk factors for acetabular labral tear. Statistical analyses were performed using the SPSS software for Windows (Version 20.0, SPSS, Chicago, IL, USA), and $p$ values of less than 0.05 were considered significant. The statistical software G*Power (version 3.1.9.7; Heinrich Heine Universität Düsseldorf, DE) was used for sample size calculation. A total of 153 subjects were required to perform logistic regression analysis using a power of 0.95 and an alpha error of 0.05 , according to a pilot study that included 50 patients; the sample size of the present study satisfied this requirement.

\section{Results}

Of 449 symptomatic hips that did not respond to conservative treatment, acetabular labral tears in 291 hips (64.8\%) were confirmed by MRI or MRA. Among them, when only 308 hips without FAI were analyzed, acetabular labral tears were confirmed in 164 hips (53.2\%). When the 141 hips with FAI were analyzed, acetabular labral tears were confirmed in 127 hips (90\%). As in previous studies [4, 8], FAI was confirmed to be a predisposing factor for acetabular labral tears due to its impinging on the anterior-superior portion of the labrum in bony deformity and abnormal articulation of FAI [17]. Additionally, the proportion of bilateral symptoms in the labral tear group was high (labral tear group vs. non-labral tear group in all patients: $38 \%$ vs. $3 \%$; labral tear group vs. non-labral tear group in patients with without FAI: $34 \%$ vs. $1 \%$ ).

Pelvic incidence was greater in the labral tear group than in the non-labral tear group $\left(52.3^{\circ} \pm 8.2^{\circ}\right.$ versus $47.1^{\circ} \pm 6.8^{\circ}$, $p<0.001$ ). Additionally, there were significant differences in age, sacral slope, pelvic tilt, FAI (cam or pincer morphology), herniation synovial pit, and cartilage denudation between the labral tear group and the non-labral tear group (Table 1). After accounting for potentially confounding variables like sex, BMI, FAI, cartilage denudation, and synovial herniation pit, we found that higher age, FAI, and high pelvic incidence were independently associated with acetabular labral tear (Table 2).

When only the patients without FAI (308 hips) were divided into groups with and without acetabular labral tear, pelvic incidence was greater in the labral tear group than in the non-labral tear group $\left(54.8^{\circ} \pm 7.6^{\circ}\right.$ versus $\left.46.8^{\circ} \pm 6.9^{\circ}, p<0.001\right)$. Additionally, there were significant differences in age, sacral slope, pelvic tilt, lateral center-edge angle, anterior center-edge angle, herniation synovial pit, and cartilage denudation between the labral tear group and the non-labral tear group (Table 3). After accounting for the potentially confounding variables, we found that higher age and high pelvic incidence were independently associated with acetabular labral tear. No differences in symptom duration, sex, or BMI were found between the two groups (Table 4). 
Table 1 Comparison of clinical patient data between the labral tear group and non-labral tear group

\begin{tabular}{|c|c|c|c|}
\hline Characteristic & $\begin{array}{l}\text { Labral tear group } \\
(N=211,291 \text { hips })\end{array}$ & $\begin{array}{l}\text { Non-labral tear group } \\
(N=154,158 \text { hips })\end{array}$ & $p$ Value \\
\hline Male patients (\%) & 139 hips $(48 \%)$ & 71 hips $(45 \%)$ & n.s \\
\hline Age (years) & $53.3 \pm 11.7$ & $48.4 \pm 11.6$ & 0.000 \\
\hline $\mathrm{BMI}\left(\mathrm{kg} / \mathrm{m}^{2}\right)$ & $23.4 \pm 2.7$ & $23.3 \pm 2.4$ & n.s \\
\hline Bilateral hip pain & 80 patients $(38 \%)$ & 4 patients $(3 \%)$ & 0.000 \\
\hline Symptom duration (months) & $8.7 \pm 3.8$ & $8.1 \pm 3.6$ & n.s \\
\hline \multicolumn{4}{|l|}{ Location of labral tears } \\
\hline Anterior-superior & $247 / 291(84.9 \%)$ & & \\
\hline Posterior-superior & $44 / 291(15.1 \%)$ & & \\
\hline \multicolumn{4}{|l|}{ Pelvic sagittal parameter } \\
\hline Pelvic incidence $\left({ }^{\circ}\right)$ & $52.3 \pm 8.2$ & $47.1 \pm 6.8$ & 0.000 \\
\hline Sacral slope $\left(^{\circ}\right)$ & $37.3 \pm 7.7$ & $35.6 \pm 5.8$ & 0.014 \\
\hline Pelvic tilt $\left({ }^{\circ}\right)$ & $15.1 \pm 6.6$ & $11.5 \pm 4.8$ & 0.000 \\
\hline \multicolumn{4}{|l|}{ Radiologic measurement } \\
\hline Lateral CEA $\left({ }^{\circ}\right)$ & $28.1 \pm 5.7$ & $27.9 \pm 3.3$ & n.s \\
\hline Anterior CEA $\left(^{\circ}\right)$ & $38.2 \pm 7$ & $38.1 \pm 4.5$ & n.s \\
\hline Alpha angle $\left(^{\circ}\right)$ & $53.5 \pm 6.3$ & $48.2 \pm 4.2$ & n.s \\
\hline Femoroacetabular impingement & 127 hips (44\%) & 14 hips $(9 \%)$ & 0.000 \\
\hline Cam type, $N(\%)$ & 92 hips $(32 \%)$ & 12 hips $(8 \%)$ & 0.000 \\
\hline Pincer type, $N(\%)$ & 22 hips $(8 \%)$ & 2 hips (1\%) & 0.000 \\
\hline Mixed type, $N(\%)$ & 13 hips (5\%) & 0 hips $(0 \%)$ & \\
\hline Normal, $N(\%)$ & 164 hips $(56 \%)$ & 144 hips $(91 \%)$ & \\
\hline Herniation synovial pit, $N(\%)$ & 35 hips (12\%) & 7 hips (4\%) & 0.009 \\
\hline Cartilage denudation, $N(\%)$ & 46 hips $(16 \%)$ & 6 hips (4\%) & 0.000 \\
\hline
\end{tabular}

Data are presented as the mean \pm standard deviation

$B M I$ body mass index, $C E A$ center-edge angle
Table 2 Results of multivariate logistic regression analyses of independent risk factors of acetabular labral tear in all patients

\begin{tabular}{lll}
\hline Factor & \multicolumn{2}{l}{ Multivariate analysis } \\
\cline { 2 - 3 } & OR (95\% CI) & $p$ Value \\
\hline Age & $1.039(1.016-1.062)$ & 0.001 \\
Sex & $1.492(0.886-2.514)$ & n.s \\
BMI & $0.980(0.892-1.077)$ & n.s \\
FAI (cam, pincer, or mixed & $15.227(7.494-30.941)$ & 0.000 \\
$\quad$ deformity) & $1.128(1.091-1.168)$ & 0.000 \\
Pelvic incidence & $2.074(0.774-5.556)$ & n.s \\
Cartilage denudation & $2.673(0.915-7.806)$ & n.s \\
Synovial herniation pit &
\end{tabular}

$B M I$ body mass index, FAI femoroacetabular impingement, $O R$ odds ratio, $C I$ confidence interval

When all of the participants were divided into two groups (pelvic incidence $>55^{\circ}$, pelvic incidence $<55^{\circ}$ ) based on earlier studies [18, 38, 41], pelvic incidence greater than $55^{\circ}$ had a sensitivity of $45.4 \%$, specificity of $86.7 \%$, positive predictive value of $86.3 \%$, and negative predictive value of $71.3 \%$ for predicting acetabular labral tears in all of the patients (Table 5). In patients without FAI, pelvic incidence greater than $55^{\circ}$ had a sensitivity of $59.8 \%$, specificity of $87.5 \%$, positive predictive value of $84.5 \%$, and negative predictive value of $65.6 \%$ for predicting acetabular labral tears (Table 6).

\section{Discussion}

The principal finding of this study was that higher age and high pelvic incidence were associated with acetabular labral tears. In particular, subgroup analysis according to the presence or absence of FAI showed that higher age and high pelvic incidence were associated with acetabular labral tears in patients without FAI. After controlling other variables, higher age and high pelvic incidence were highly associated with acetabular labral tears. Additionally, pelvic incidence greater than $55^{\circ}$ in a standing lumbosacral lateral radiograph predicts an increase in the possibility of acetabular labral tear in patients with hip pain who do not respond to conservative treatment. Because $48-95 \%$ of acetabular labral tears are associated with substantial damage to the acetabular cartilage, higher age and degeneration based on 
Table 3 Subgroup comparison of clinical data between the labral tear group and non-labral tear group in patients without femoroacetabular impingement

\begin{tabular}{llll}
\hline Characteristic & $\begin{array}{l}\text { Labral tear group } \\
(N=122,164 \text { hips })\end{array}$ & $\begin{array}{l}\text { Non-labral tear group } \\
(N=142,144 \text { hips })\end{array}$ & $p$ Value \\
\hline Male patients $(\%)$ & 53 hips $(32 \%)$ & 62 hips $(43 \%)$ & n.s \\
Age $($ years $)$ & $54.4 \pm 11.2$ & $48.7 \pm 11.6$ & 0.000 \\
BMI $\left(\mathrm{kg} / \mathrm{m}^{2}\right)$ & $23.3 \pm 2.8$ & $23.3 \pm 2.4$ & n.s \\
Bilateral hip pain & 42 patients $(34 \%)$ & 2 patients $(1 \%)$ & 0.000 \\
Symptom duration (months) & $8.8 \pm 3.9$ & $8.1 \pm 3.4$ & n.s \\
Location of labral tears & & & \\
Anterior-superior & $143 / 164(87.2 \%)$ & & \\
Posterior-superior & $21 / 164(12.8 \%)$ & & 0.000 \\
Pelvic sagittal parameter & & & 0.000 \\
Pelvic incidence $\left({ }^{\circ}\right)$ & $54.8 \pm 7.6$ & $46.8 \pm 6.9$ & 0.000 \\
Sacral slope $\left(^{\circ}\right)$ & $38.6 \pm 8.1$ & $35.7 \pm 5.8$ & \\
Pelvic tilt $\left({ }^{\circ}\right)$ & $16.5 \pm 7.2$ & $11.3 \pm 4.7$ & 0.040 \\
Radiologic measurement & & & 0.011 \\
Lateral CEA $\left(^{\circ}\right)$ & $26.8 \pm 5.5$ & $27.9 \pm 3.2$ & n.s \\
Anterior CEA $\left(^{\circ}\right)$ & $35.6 \pm 5.9$ & $38.0 \pm 4.3$ & 0.009 \\
Alpha angle $\left(^{\circ}\right)$ & $47.8 \pm 5.5$ & $47.4 \pm 2.6$ & 0.000 \\
Herniation synovial pit, $N(\%)$ & 12 hips $(7 \%)$ & 3 hips $(5 \%)$ & \\
Cartilage denudation, $N(\%)$ & 21 hips $(13 \%)$ & & \\
\hline
\end{tabular}

Data are presented as the mean \pm standard deviation

$B M I$ body mass index, $C E A$ center-edge angle
Table 4 Results of multivariate logistic regression analyses of independent risk factors of acetabular labral tear in patients without femoroacetabular impingement

\begin{tabular}{lll}
\hline Factor & \multicolumn{2}{l}{ Multivariate analysis } \\
\cline { 2 - 3 } & OR (95\% CI) & $p$ Value \\
\hline Age & $1.034(1.009-1.059)$ & 0.008 \\
Sex & $1.456(0.816-2.597)$ & n.s \\
BMI & $0.958(0.864-1.061)$ & n.s \\
Pelvic incidence & $1.145(1.102-1.190)$ & 0.000 \\
Cartilage denudation & $4.003(1.002-15.996)$ & n.s \\
Synovial herniation pit & $1.669(0.484-5.965)$ & n.s \\
\hline
\end{tabular}

$B M I$ body mass index, $O R$ odds ratio, $C I$ confidence interval

Table 5 Analysis of pelvic incidence and acetabular labral tears in all patients (449 hips)

\begin{tabular}{llll}
\hline Pelvic incidence & Labral tear group & $\begin{array}{l}\text { Non-labral } \\
\text { tear group }\end{array}$ & Total \\
\hline$>55^{\circ}$ & 132 hips & 21 hips & 153 hips \\
$<55^{\circ}$ & 159 hips & 137 hips & 296 hips \\
Total & 291 hips & 158 hips & 449 hips \\
Statistics & & Estimate & \\
Sensitivity & & $45.4 \%$ & \\
Specificity & $86.7 \%$ & \\
Positive predictive value & & $86.3 \%$ & \\
Negative predictive value & & $71.3 \%$ & \\
\hline
\end{tabular}

Table 6 Analysis of pelvic incidence and acetabular labral tears in patients without femoroacetabular impingement (308 hips)

\begin{tabular}{llll}
\hline Pelvic incidence & Labral tear group & $\begin{array}{l}\text { Non-labral } \\
\text { tear group }\end{array}$ & Total \\
\hline$>55^{\circ}$ & $98 \mathrm{hips}$ & $18 \mathrm{hips}$ & $116 \mathrm{hips}$ \\
$<55^{\circ}$ & $66 \mathrm{hips}$ & $126 \mathrm{hips}$ & $192 \mathrm{hips}$ \\
Total & $164 \mathrm{hips}$ & $144 \mathrm{hips}$ & $308 \mathrm{hips}$ \\
Statistics & & Estimate & \\
Sensitivity & & $59.8 \%$ & \\
Specificity & $87.5 \%$ & \\
Positive predictive value & & $84.5 \%$ & \\
Negative predictive value & & $65.6 \%$ & \\
\hline
\end{tabular}

radiographic arthritic change are considered to be risk factors for acetabular labral tears [2, 9, 12, 27]. However, little is known about the effect of pelvic sagittal parameters such as PI on acetabular labral tears. High pelvic incidence was associated with acetabular labral tears after controlling for age, sex, BMI, FAI, cartilage denudation, and synovial herniation pit. Since high pelvic incidence and biomechanical adaptations may contribute to the excessive stress experienced by the hip joint and acetabular labrum, the evaluation of pelvic incidence in patients with hip pain could help to assess the possibility of acetabular labral tears $[15,16]$.

Although there is some controversy, pelvic incidence has been considered as a specific morphological parameter for 
each patient, since it does not change in the external pelvic position [24]. High pelvic incidence means theoretically increased lumbar lordosis, and in attempts to compensate from the increased mechanical loading of lumbar lordosis and maintain sagittal balance, high pelvic incidence is accompanied by posterior pelvic tilt [43]. This posterior tilt of the pelvis resulted in decreased femoral head anterior coverage by creating a more vertical articular surface of the acetabulum. In this way, excessive mechanical stress will be applied to the mainly anterior labrum of the acetabulum, which would increase the occurrence of acetabular labral tears $[6,13,37]$. In particular, $84.9 \%$ of the acetabular labral tears in this study were located in the anterior-superior portion of the labrum, which may be thought to be influenced by the increase in mechanical load to the anterior portion of the labrum and due to the high pelvic incidence. Therefore, we suggested in this study that high pelvic incidence could potentially be associated with the development of acetabular labral tears, especially in patients without FAI, even though FAI was confirmed to be the most predisposing factor of acetabular labral tears.

Previous studies have examined the influence of abnormal pelvic incidence (high or low pelvic incidence) on hip joints, resulting in conditions such as hip osteoarthritis, FAI, or osteonecrosis of the femoral head [10, 11, 18]. In particular, acetabular over-coverage is associated with FAI, and it is known to be related to acetabular labral tears [17]. Low pelvic incidence does not allow for modification of the pelvic motion, so amplified force is applied to the femoroacetabular joint, thus resulting in impingement and acetabular labral tears [10]. However, our investigations in the present study revealed that not only low pelvic incidence but also high pelvic incidence is associated with acetabular labral tears in patients with a symptomatic hip. Because abnormal spinopelvic parameters could affect hip joints, analysis of spinopelvic parameters and sagittal imbalance should not be underestimated or poorly determined by a hip surgeon.

There were several limitations to this study. First, this study had a retrospective design and a relatively small number of patients, which could be associated with a risk of bias in analysis. Moreover, due to the nature of the retrospective study, it was difficult to accurately compare with a true control group. In addition, higher age was a very important factor regardless of the presence of osteoarthritis in the acetabular labral tear, and this study was limited in that the two groups were not properly matched by age. Second, the subjects were only those who did not respond to 3 months of conservative treatment; however, the duration of symptoms varied from 3 to 18 months. Although there was no difference in symptom duration between the groups with and without acetabular labral tear, the various symptom durations may have influenced the outcome. In addition, it is possible that hip pain or groin pain does not indicate a labral tear but rather a symptom caused by internal snapping or extra-articular structure, and there was no confirmation process, such as injection, to determine whether pain of intra-articular origin was recognized. Third, since the present study was conducted on Koreans, it may be difficult to generalize to other populations. Additionally, acetabular labral tear in this study was based on the diagnosis on MRI or MRA, not arthroscopic confirmation. Therefore, there may be bias depending on whether MRI or MRA was used, and chondrolabral separation or intrasubstance tearing can lead to the overdiagnosis as acetabular labral tears.

\section{Conclusion}

Acetabular labral tear is associated with high pelvic incidence with or without FAI morphology. The assessment of pelvis incidence and FAI morphology in patients with hip pain may help surgeons to evaluate acetabular labral tears.

Funding There was no funding for this study.

\section{Declarations}

Conflict of interest The authors declare that they have no competing interests.

Ethical review committee statement Approved by the Institutional Review Board of Yongin Severance Hospital, IRB \# 9-2020-0051).

Open Access This article is licensed under a Creative Commons Attribution 4.0 International License, which permits use, sharing, adaptation, distribution and reproduction in any medium or format, as long as you give appropriate credit to the original author(s) and the source, provide a link to the Creative Commons licence, and indicate if changes were made. The images or other third party material in this article are included in the article's Creative Commons licence, unless indicated otherwise in a credit line to the material. If material is not included in the article's Creative Commons licence and your intended use is not permitted by statutory regulation or exceeds the permitted use, you will need to obtain permission directly from the copyright holder. To view a copy of this licence, visit http://creativecommons.org/licenses/by/4.0/.

\section{References}

1. Beall DP, Sweet CF, Martin HD, Lastine CL, Grayson DE, Ly JQ, Fish JR (2005) Imaging findings of femoroacetabular impingement syndrome. Skelet Radiol 34(11):691-701

2. Beaule PE, O'Neill M, Rakhra K (2009) Acetabular labral tears. J Bone Jt Surg Am 91(3):701-710

3. Beaule PE, Zaragoza E, Motamedi K, Copelan N, Dorey FJ (2005) Three-dimensional computed tomography of the hip in the assessment of femoroacetabular impingement. J Orthop Res 23(6): 1286-1292

4. Bedi A, Kelly BT (2013) Femoroacetabular impingement. J Bone Jt Surg Am 95(1):82-92 
5. Bharam S (2006) Labral tears, extra-articular injuries, and hip arthroscopy in the athlete. Clin Sports Med 25(2):279-292

6. Chen HF, Zhao CQ (2018) Pelvic incidence variation among individuals: functional influence versus genetic determinism. J Orthop Surg Res 13(1):59

7. Clohisy JC, Carlisle JC, Beaule PE, Kim YJ, Trousdale RT, Sierra RJ, Leunig M, Schoenecker PL, Millis MB (2008) A systematic approach to the plain radiographic evaluation of the young adult hip. J Bone Jt Surg Am 90(Suppl 4):47-66

8. Crawford MJ, Dy CJ, Alexander JW, Thompson M, Schroder SJ, Vega CE, Patel RV, Miller AR, McCarthy JC, Lowe WR, Noble PC (2007) The 2007 Frank Stinchfield Award. The biomechanics of the hip labrum and the stability of the hip. Clin Orthop Relat Res 465:16-22

9. Dumont GD, Ergen TJ, Pacana MJ, Money AJ, Menge TJ, Barnes AJ (2020) Patient-specific factors are associated with severity of chondrolabral injury in patients with femoroacetabular impingement. Knee Surg Sports Traumatol Arthrosc 28(10):3376-3381

10. Gebhart JJ, Streit JJ, Bedi A, Bush-Joseph CA, Nho SJ, Salata MJ (2014) Correlation of pelvic incidence with cam and pincer lesions. Am J Sports Med 42(11):2649-2653

11. Gebhart JJ, Weinberg DS, Bohl MS, Liu RW (2016) Relationship between pelvic incidence and osteoarthritis of the hip. Bone Jt Res $5(2): 66-72$

12. Honda E, Utsunomiya H, Hatakeyama A, Nakashima H, Suzuki H, Matsuda DK, Sakai A, Uchida S (2020) Patients aged in their 70 s do not have a high risk of progressive osteoarthritis following arthroscopic femoroacetabular impingement correction and labral preservation surgery. Knee Surg Sports Traumatol Arthrosc 28(5):1648-1655

13. Hong JY, Suh SW, Modi HN, Hur CY, Yang JH, Song HR (2010) Correlation of pelvic orientation with adult scoliosis. J Spinal Disord Tech 23(7):461-466

14. Ike H, Dorr LD, Trasolini N, Stefl M, McKnight B, Heckmann N (2018) Spine-Pelvis-Hip relationship in the functioning of a total hip replacement. J Bone Jt Surg Am 100(18):1606-1615

15. Innmann MM, Merle $C$, Phan $P$, Beaule PE, Grammatopoulos $G$ (2021) Differences in spinopelvic characteristics between hip osteoarthritis patients and controls. J Arthroplasty 36(8):2808-2816

16. Kechagias VA, Grivas TB, Papagelopoulos PJ, Kontogeorgakos VA, Vlasis K (2021) Truncal changes in patients suffering severe hip or knee osteoarthritis: a surface topography study. Clin Orthop Surg 13(2):185-195

17. Kelly BT, Weiland DE, Schenker ML, Philippon MJ (2005) Arthroscopic labral repair in the hip: surgical technique and review of the literature. Arthroscopy 21(12):1496-1504

18. Kwon HM, Yang IH, Park KK, Cho BW, Kam JH, Kong Y, Yang JH, Lee WS (2020) High pelvic incidence is associated with disease progression in nontraumatic osteonecrosis of the femoral head. Clin Orthop Relat Res 478(8):1870-1876

19. Landis JR, Koch GG (1977) The measurement of observer agreement for categorical data. Biometrics 33(1):159-174

20. Lazennec JY, Brusson A, Rousseau MA (2011) Hip-spine relations and sagittal balance clinical consequences. Eur Spine J 20(Suppl 5):686-698

21. Lee YK, Kim JM, Yoon BI, Kim JY, Lee GY, Kim S, Ha YC (2019) Location and correlation of acetabular labral tears and paralabral cysts using magnetic resonance imaging or magnetic resonance arthrography in patients with femoroacetabular impingement. Arthroscopy 35(3):809-815

22. Legaye J, Duval-Beaupere G, Hecquet J, Marty C (1998) Pelvic incidence: a fundamental pelvic parameter for three-dimensional regulation of spinal sagittal curves. Eur Spine J 7(2):99-103

23. Linda DD, Naraghi A, Murnaghan L, Whelan D, White LM (2017) Accuracy of non-arthrographic 3T MR imaging in evaluation of intra-articular pathology of the hip in femoroacetabular impingement. Skelet Radiol 46(3):299-308

24. Mac-Thiong JM, Berthonnaud E, Dimar JR 2nd, Betz RR, Labelle $\mathrm{H}$ (2004) Sagittal alignment of the spine and pelvis during growth. Spine (Phila Pa 1976) 29(15):1642-1647

25. McCarthy J, Noble P, Aluisio FV, Schuck M, Wright J, Lee JA (2003) Anatomy, pathologic features, and treatment of acetabular labral tears. Clin Orthop Relat Res 406:38-47

26. McCarthy JC, Noble PC, Schuck MR, Wright J, Lee J (2001) The Otto E. Aufranc Award: the role of labral lesions to development of early degenerative hip disease. Clin Orthop Relat Res 393:25-37

27. McCarthy JC, Noble PC, Schuck MR, Wright J, Lee J (2001) The watershed labral lesion: its relationship to early arthritis of the hip. J Arthroplasty 16(8 Suppl 1):81-87

28. Mygind-Klavsen B, Lund B, Nielsen TG, Maagaard N, Kraemer O, Hölmich P, Winge S, Lind M (2019) Danish Hip Arthroscopy Registry: predictors of outcome in patients with femoroacetabular impingement (FAI). Knee Surg Sports Traumatol Arthrosc 27(10):3110-3120

29. Mygind-Klavsen B, Nielsen TG, Lund B, Lind M (2021) Clinical outcomes after revision hip arthroscopy in patients with femoroacetabular impingement syndrome (FAIS) are inferior compared to primary procedures. Results from the Danish Hip Arthroscopy Registry (DHAR). Knee Surg Sports Traumatol Arthrosc 29(4):1340-1348

30. Narvani AA, Tsiridis E, Tai CC, Thomas P (2003) Acetabular labrum and its tears. Br J Sports Med 37(3):207-211

31. Notzli HP, Wyss TF, Stoecklin CH, Schmid MR, Treiber K, Hodler J (2002) The contour of the femoral head-neck junction as a predictor for the risk of anterior impingement. J Bone Jt Surg Br 84(4):556-560

32. Pfirrmann CW, Duc SR, Zanetti M, Dora C, Hodler J (2008) MR arthrography of acetabular cartilage delamination in femoroacetabular cam impingement. Radiology 249(1):236-241

33. Pitt MJ, Graham AR, Shipman JH, Birkby W (1982) Herniation pit of the femoral neck. AJR Am J Roentgenol 138(6):1115-1121

34. Quinlan NJ, Alpaugh K, Upadhyaya S, Conaway WK, Martin SD (2019) Improvement in functional outcome scores despite persistent pain with 1 year of nonsurgical management for acetabular labral tears with or without femoroacetabular impingement. Am J Sports Med 47(3):536-542

35. Register B, Pennock AT, Ho CP, Strickland CD, Lawand A, Philippon MJ (2012) Prevalence of abnormal hip findings in asymptomatic participants: a prospective, blinded study. Am J Sports Med 40(12):2720-2724

36. Reiman MP, Mather RC 3rd, Hash TW 2nd, Cook CE (2014) Examination of acetabular labral tear: a continued diagnostic challenge. Br J Sports Med 48(4):311-319

37. Ross JR, Nepple JJ, Philippon MJ, Kelly BT, Larson CM, Bedi A (2014) Effect of changes in pelvic tilt on range of motion to impingement and radiographic parameters of acetabular morphologic characteristics. Am J Sports Med 42(10):2402-2409

38. Saltychev M, Pernaa K, Seppanen M, Makela K, Laimi K (2018) Pelvic incidence and hip disorders. Acta Orthop 89(1):66-70

39. Sutter R, Dietrich TJ, Zingg PO, Pfirrmann CW (2012) How useful is the alpha angle for discriminating between symptomatic patients with cam-type femoroacetabular impingement and asymptomatic volunteers? Radiology 264(2):514-521

40. Vahedi H, Aalirezaie A, Azboy I, Daryoush T, Shahi A, Parvizi J (2019) Acetabular labral tears are common in asymptomatic contralateral hips with femoroacetabular impingement. Clin Orthop Relat Res 477(5):974-979

41. Weinberg DS, Morris WZ, Gebhart JJ, Liu RW (2016) Pelvic incidence: an anatomic investigation of 880 cadaveric specimens. Eur Spine J 25(11):3589-3595 
42. Wyles CC, Heidenreich MJ, Jeng J, Larson DR, Trousdale RT, Sierra RJ (2017) The John Charnley Award: redefining the natural history of osteoarthritis in patients with hip dysplasia and impingement. Clin Orthop Relat Res 475(2):336-350

43. Yoshimoto H, Sato S, Masuda T, Kanno T, Shundo M, Hyakumachi T, Yanagibashi Y (2005) Spinopelvic alignment in patients with osteoarthrosis of the hip: a radiographic comparison to patients with low back pain. Spine (Phila Pa 1976) 30(14):1650-1657

44. Zhou J, Melugin HP, Hale RF, Leland DP, Bernard CD, Levy BA, Krych AJ (2020) The prevalence of radiographic findings of structural hip deformities for femoroacetabular impingement in patients with hip pain. Am J Sports Med 48(3):647-653

Publisher's Note Springer Nature remains neutral with regard to jurisdictional claims in published maps and institutional affiliations. 